\title{
CONSELHO FEDERAL DE ENFERMAGEM: GOVERNANÇA E GESTÃO ESTRATÉGICA ORIENTADA PARA RESULTADOS DAS ATIVIDADES FINALÍSTICAS
}

Marcelo Felipe Moreira Persegona ${ }^{1}$ Manoel Carlos Neri da Silva ${ }^{1}$ Neyson Pinheiro Freire ${ }^{2}$ Walkirio Costa Almeida ${ }^{1}$ Michely Filete ${ }^{1}$ Gilney Guerra de Medeiros ${ }^{1}$ Antônio Marcos Freire Gomes ${ }^{1}$ David Lopes Neto ${ }^{2}$

\author{
https://orcid.org/0000-0002-8430-9317 \\ https://orcid.org/0000-0002-3923-7473 \\ https://orcid.org/0000-0002-9038-9974 \\ https://orcid.org/0000-0001-9260-7982 \\ https://orcid.org/0000-0002-8960-7444 \\ https://orcid.org/0000-0002-3351-284 \\ https://orcid.org/0000-0003-1724-6616 \\ https://orcid.org/0000-0002-0677-0853
}

Objetivo: discorrer sobre o processo de governança e gestão estratégica orientada para resultados das atividades finalísticas e administrativas do sistema Conselho Federal de Enfermagem (Cofen) e Conselhos Regionais de Enfermagem (Corens). Metodologia: estudo exploratório-descritivo, documental fundamentado em dados coletados em arquivos, especialmente, relatórios de gestão do Cofen. Resultados: evidencia que as ações do Cofen orientam os Corens para a boa e regular aplicação dos recursos públicos, cumprimento da missão institucional e realização das atividades finalisticas por meio de um trabalho integrado e baseado no planejamento estratégico institucional. Conclusão: Em síntese, o artigo apresenta os resultados das atividades finalísticas de inscrição, cadastro e registro de profissionais de enfermagem; fiscalização e processos éticos e disciplinares pelo sistema, a estrutura organizacional componente gerencial para cumprir as atividades finalisticas e a importância dos procedimentos metodológicos adotados para execução do planejamento estratégico institucional.

Descritores: Enfermagem; Governança; Organização e Administração; Estratégias; Planejamento Estratégico.

\section{FEDERAL NURSING COUNCIL: GOVERNANCE AND STRATEGIC MANAGEMENT ORIENTED FOR RESULTS OF FINALISTIC ACTIVITIES}

Objective: to discuss the governance and strategic management process oriented towards results of the finalistic and administrative activities of the Federal Council of Nursing (Cofen) and Regional Nursing Councils (Coren) system. Methodology: exploratory-descriptive, documentary study based on data collected in files, especially Cofen management reports. Results: it shows that Cofen's actions guide the Coren towards the good and regular use of public resources, the fulfillment of the institutional mission and the carrying out of final activities through an integrated work based on institutional strategic planning. Conclusion: In summary, the article presents the results of the final activities of registration, registration and registration of nursing professionals; inspection and ethical and disciplinary processes by the system, the organizational structure and managerial component to fulfill the finalistic activities and the importance of the methodological procedures adopted for the execution of the institutional strategic planning.

Descriptors: Nursing; Governance; Organization and Administration; Strategies; Strategic Planning.

\section{CONSEJO FEDERAL DE ENFERMERÍA: GOBERNANZA Y GESTIÓN ESTRATÉGICA ORIENTADA A LOS RESULTADOS DE LAS ACTIVIDADES}

\section{FINALISTAS}

Objetivo: discutirel proceso de gobernanzay gestión estratégica orientado a los resultados delas actividades finalistasy administrativas del sistema del Consejo Federal de Enfermería (Cofen) y los Consejos Regionales de Enfermería (Corens). Metodología: estudio documental exploratorio descriptivo basado en datos recopilados en archivos, especialmente informes de gestión de Cofen. Resultados: muestra que las acciones de Cofen guían a los Corens hacia el uso bueno y regular de los recursos públicos, el cumplimiento de la misión institucional y la realización de las actividades finales a través de un trabajo integrado basado en la planificación estratégica institucional. Conclusión: en resumen, el artículo presenta los resultados de las actividades finales de registro, registro y registro de profesionales de enfermeria; inspección y procesos éticos y disciplinarios por parte del sistema, el componente organizacional y la estructura gerencial para cumplir con las actividades finalistas y la importancia de los procedimientos metodológicos adoptados para la ejecución de la planificación estratégica institucional.

Descriptores: Enfermería; Gobernanza; Organización y Administración; Estrategias; Planificación Estratégica. 


\section{INTRODUÇÃO}

A estrutura organizacional do Sistema Cofen/Conselhos Regionais de Enfermagem como uma autarquia pública sui generis lhe confere a função precipua de estabelecer diretrizes normativas aos Conselhos Regionais de Enfermagem para fiscalizarem o exercício da profissão, de acordo com a Lei $n^{\circ}$ 7.498 , de 25/06/1986 ${ }^{2}$. Neste sentido, o Conselho Federal de Enfermagem (Cofen) fortaleceu institucionalmente as áreas finalísticas dos Conselhos Regionais de Enfermagem com a criação de um departamento específico e a consolidação da Força Nacional de Fiscalização para reduzir as assimetrias e assegurar a fiscalização efetiva em todos estados do Brasil, utilizando-se de estratégias por plenárias descentralizadas, que contribuem para a integração do Cofen/Conselhos Regionais de Enfermagem, bem como a realização de encontros setoriais e fomentos de grupo de trabalho, tendo em vista o alinhamento estratégico do sistema.

Dessa maneira, para o atendimento de suas finalidades, - Sistema Cofen/Conselhos Regionais de Enfermagem exerce ações deliberativas, administrativas, executivas, normativas, regulamentares, contenciosas e disciplinares ${ }^{3}$.

O Cofen, com sede na capital federal e jurisdição em todo o território nacional, é a unidade central do Sistema e os Conselhos Regionais de Enfermagem (Corens) as unidades vinculadas com jurisdição no Distrito Federal e nos Estados onde se localizam, com sede e foro nas respectivas capitais.

O movimento de boa governança pública tem ascendido como um artificio baseado nos princípios a legitimidade, a equidade, a responsabilidade, a eficiência, a probidade, a transparência e a accountability ${ }^{4}$, os quais são capazes de expressar participação proativa de gestores, notadamente pelo uso de metodologias orientadas para resultados baseados no planejamento estratégico institucional para cumprimento das atividades finalisticas.

Este estudo tem por objetivo discorrer sobre o processo de governança e gestão estratégica orientada para resultados das atividades finalísticas e administrativas do sistema Conselho Federal de Enfermagem (Cofen) e Conselhos Regionais de Enfermagem (Corens).

\section{METODOLOGIA}

Tipo de estudo - Estudo qualitativo, de natureza exploratório-descritiva, do tipo documental.

População e amostra - A pesquisa foi realizada em fontes de dados de relatórios de gestão da estrutura administrativa do Cofen. Foram incluídos os relatórios provenientes da Assessoria de Planejamento e Gestão, da Divisão de Fiscalização do Exercício Profissional, da Divisão de Orçamento e Empenho/Departamento Financeiro e do Departamento de Gestão do Exercício Profissional/Setor de Processos Éticos. Foram excluídas as informações do relatório de gestão de 2019 .

Local de estudo - A documentação foi consultada na sede do Cofen.

Coleta dos dados - Os dados foram coletados entre em janeiro e fevereiro de 2020, formalizando o corpus documental em seis eixos temáticos: 1 - Organização do Sistema Cofen/Conselhos Regionais de Enfermagem 2 - Finalidade e competências do Sistema Cofen/ Conselhos Regionais de Enfermagem; 3 - Governança institucional do Cofen; 4 - Cadeia de valor e modelo de negócios; 5 - Metodologia de Gestão Estratégica Orientada para Resultados (GEOR); 6 - Atividades finalísticas e administrativas, os quais receberam uma análise descritiva.

\section{RESULTADOS}

\section{Organização do Sistema Cofen/Conselhos Regionais de}

\section{Enfermagem}

Os Corens são classificados conforme critérios estabelecidos na Decisão Cofen n²43/2016, sendo: micro, pequeno, médio, grande e macro porte. A classificação se dá utilizando o número de profissionais inscritos no Coren (Figura 1). O porte dos Corens está identificado por cores: macro porte pela cor laranja, grande porte pela cor lilás, médio porte pela cor amarela, pequeno porte pela cor rosa e micro porte pela cor azul.

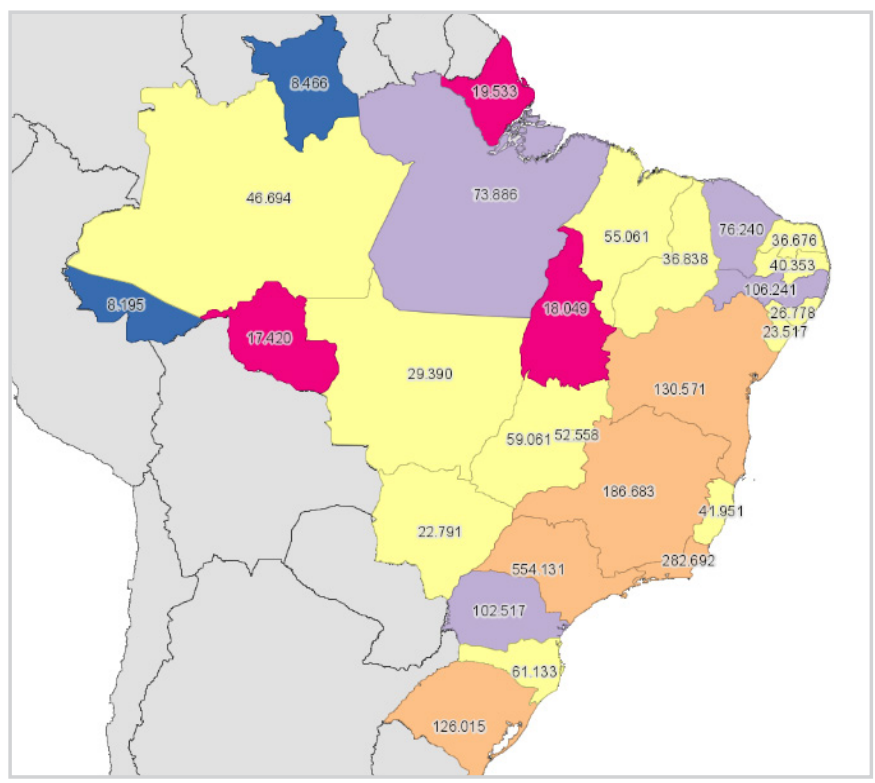

Figura 1 - Cartograma dos portes dos Corens por número de inscritos.

Fonte: Divisão de Fiscalização do Exercício Profissional/ DGEP/Cofen. 
São classificados como de micro porte os Corens de Roraima e Acre, que têm até 10 mil profissionais de enfermagem inscritos. Com 10 mil a 20 mil, os Corens do Amapá, Rondônia, Tocantins, Sergipe e Mato Grasso do Sul foram classificados como de pequeno porte. A classificação considera de médio porte os Corens com mais de 20 mil e menos de 60 mil inscritos: Alagoas, Mato Grosso, Rio Grande do Norte, Piauí, Paraíba, Espírito Santo, Amazonas, Distrito Federal, Maranhão, Goiás, Santa Catarina e Pará, de grande porte aqueles com até 120 mil inscritos: Ceará, Pernambuco, Paraná, Bahia e Rio Grande do Sul e, de macro porte, os regionais com mais de 120 mil profissionais inscritos: Minas Gerais, Rio de Janeiro e São Paulo.

Esta classificação auxilia na redução das assimetrias regionais garantindo que todos os Corens tenham as condições mínimas necessárias para cumprir sua missão de fiscalizar o exercício profissional da enfermagem, garantindo a segurança de pacientes e profissionais. O apoio logístico e técnico aos regionais menor porte é um compromisso da atual gestão do Cofen.

\section{Finalidade e Competências do Sistema Cofen/ Conselhos Regionais de Enfermagem}

O Sistema Cofen/Conselhos Regionais de Enfermagem, criado pela Lei no 5.905, de 12 de julho de 1973, é constituido pelo conjunto das autarquias federais fiscalizadoras do exercício da profissão de enfermagem e tem por finalidade a normatização, disciplinarização e fiscalização do exercício da Enfermagem e da observância de seus princípios éticos profissionais. Cada Conselho é dotado de personalidade jurídica de direito público, com autonomia administrativa, financeira, patrimonial, orçamentária e política, sem qualquer vínculo funcional ou hierárquico com os órgãos da Administração Pública Federal5.

O mapeamento da localização do Cofen (Figura 2) está representada pela estrela amarela no Distrito Federal; os 27 Conselhos Regionais de Enfermagem (Corens) estão representados pelos pontos vermelhos; e as 102 subseções estão representadas pelos pontos azuis.

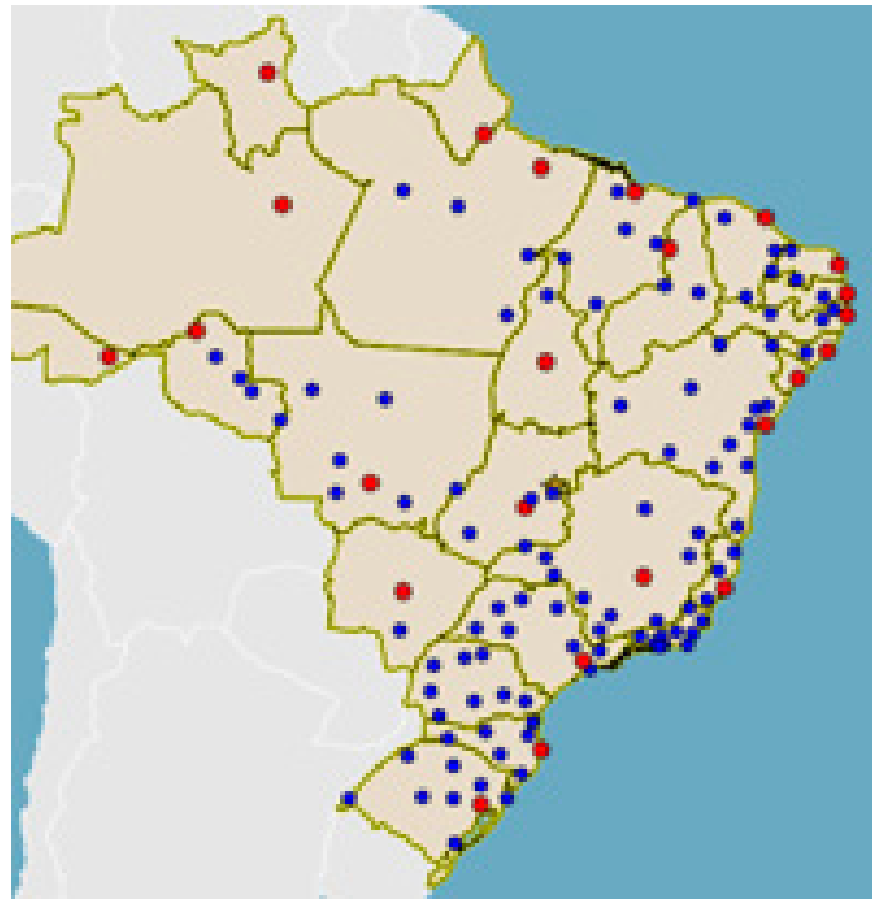

Figura 2 - Abrangência do Sistema Cofen/Conselhos Regionais de Enfermagem.

Fonte: Assessoria de Planejamento e Gestão/Cofen.

Quanto a compreensão das finalidades das entidades de classe da enfermagem brasileira, faz-se necessário observar que nem todo profissional de enfermagem e grande parte da sociedade sabe a diferença entre Conselho de Fiscalização Profissional, Associação e Sindicato. Em uma breve descrição, a diferença entre essas entidades é:

- Conselho de Fiscalização Profissional: O Sistema Cofen/Conselhos Regionais de Enfermagem se constitui num conjunto de autarquias federais que tem a missão finalística de registro, fiscalização, normatização, julgamento ético e orientação do exercício da enfermagem. O Cofen é o órgão central do Sistema responsável por baixar normas gerais para orientar a fiscalização, disciplinar o exercício da profissão, expedir instruções e supervisionar o bom funcionamento dos Conselhos Regionais, além de propor políticas para o desenvolvimento da enfermagem. Já os Conselhos Regionais são órgãos subordinados ao Conselho Federal e executores de suas instruções e da disciplina e fiscalização do exercício profissional. Sendo assim, o público-alvo 
do Conselho Federal são os Conselhos Regionais diretamente e os profissionais de enfermagem indiretamente. Ressalta-se que o Conselho Federal e os Conselhos Regionais de Enfermagem têm seu espaço de atuação delimitado pela sua lei de sua criação

- Associação: Pessoa jurídica de direito privado, responsável por congregar os profissionais de determinada área/profissão, visando atualização e aprimoramento profissional, por meio da promoção de eventos, cursos, criação de grupos de trabalho por temas etc. Também atua na divulgação da área/profissão, visando abrir vagas no mercado de trabalho, podendo disponibilizar bancos de currículos e divulgar vagas. Possui cunho científico e o objetivo de reciclar os conhecimentos.

- Sindicato: Pessoa jurídica de direito privado, que tem sua ação voltada para as questões referentes à relação de trabalho, tais como salário, horas extras, insalubridade, acordos e dissídios coletivos, entre outras questões trabalhistas. Entidade constituída para fins de proteção, estudo e defesa de interesses comuns de seus filiados.

O Sistema Cofen/Conselhos Regionais de Enfermagem tem sob sua responsabilidade a gestão 2.263.269 profissionais de Enfermagem6, sendo 552.353 Enfermeiros, 1.295.011 Técnicos de Enfermagem, 415.619 Auxiliares de Enfermagem e 286 Obstetrizes presentes em todos os municípios brasileiros com papel essencial no Sistema Único de Saúde (SUS), em todos os níveis de atenção (primária, secundária e terciária).

Para gerir todos os profissionais de enfermagem inscritos, o Sistema Cofen/Conselhos Regionais de Enfermagem conta com 2.704 profissionais de diversas áreas do conhecimento. O Cofen, por sua vez, possui sua força de trabalho com 276 profissionais.

\section{Governança Institucional do Cofen}

A governança institucional é a maneira pela qual o Cofen exerce a administração dos seus recursos humanos e orçamentários visando o cumprimento das suas atividades finalísticas, implicando ainda na sua capacidade de planejar, formular e implementar políticas públicas e cumprir suas competências institucionais.

Dentro do quadro situacional do Cofen, a governança é entendida como o conjunto de mecanismos de liderança, estratégia e controle postos em prática para avaliar, direcionar e monitorar a gestão do Sistema Cofen/ Conselhos Regionais de Enfermagem, com vistas à condução de políticas públicas e à prestação de serviços de interesse da sociedade.

Portanto, a governança institucional do Cofen compreende, essencialmente, os mecanismos de liderança, estratégia e controle postos em prática para avaliar, direcionar e monitorar a atuação da gestão, com vistas à condução de políticas públicas e à prestação de serviços de interesse da sociedade e da enfermagem brasileira (Figura 3)

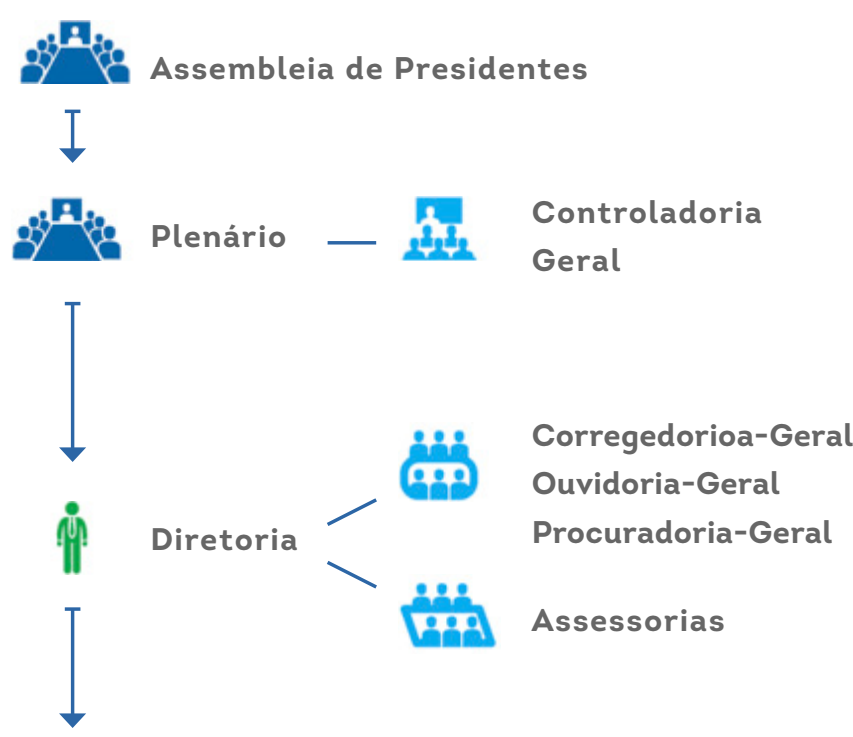

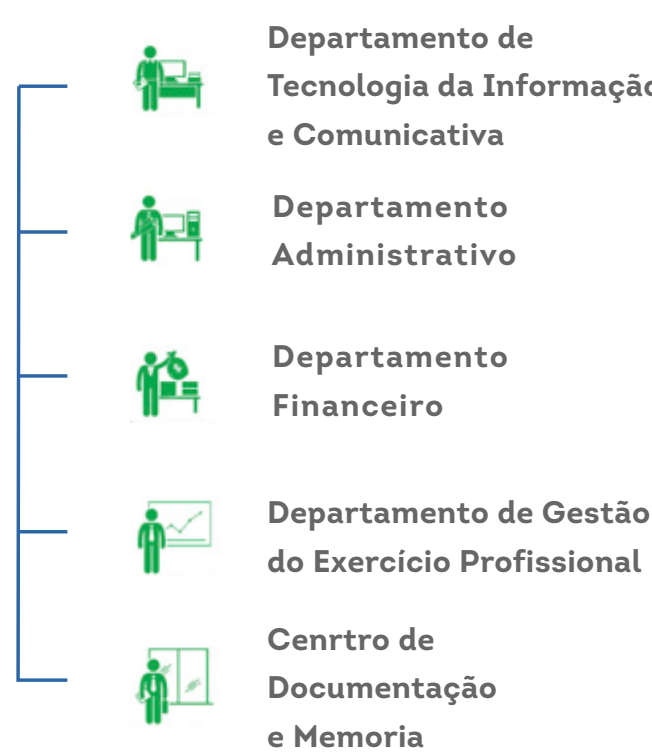

Figura 3 - Processo de Governança Institucional do Cofen.

Fonte: Assessoria de Planejamento e Gestão/Cofen. 
O Regimento Interno do Cofen explicita como é organizada e instituída a Governança Institucional. Este regimento, aprovado pela Resolução Cofen no 421/2012, institui a Assembleia de Presidentes como órgão consultivo e recursal do Sistema Cofen/Conselhos Regionais de Enfermagem. Esta mesma Resolução também institui e disciplina o funcionamento do Plenário e da Diretoria do Cofen $^{3}$.

A Assembleia de Presidentes é constituida pelo conjunto de presidentes dos Conselhos Federal e Regionais de Enfermagem. Ela delibera, pelo voto da maioria de seus integrantes, a respeito de julgamento de recursos das Decisões proferidas pelo Cofen em Processo Administrativo Disciplinar contra conselheiros ou em Processo Ético; definição de macro políticas do Sistema Cofen/Conselhos Regionais de Enfermagem; e consultas formuladas pelo Plenário e presidente do Cofen.
O Plenário do Cofen está constituido por dezoito Conselheiros Federais, os quais estão divididos em nove Conselheiros Federais Efetivos e nove Suplentes. Dos nove Efetivos, seis compõem a Diretoria do Cofen. A Diretoria do Cofen é constituida por Conselheiros Federais Efetivos que ocupam os cargos de: Presidente, Vice-Presidente, Primeiro-Secretário, Segundo-Secretário, PrimeiroTesoureiro e Segundo-Tesoureiro.

\section{Cadeia de Valor e Modelo de Negócios}

A Cadeia de Valor do Cofen foi elaborada a partir dos elementos básicos do Planejamento Estratégico Institucional (PEI), atividades finalísticas, diretivas de conformidade e recursos institucionais (Figura 4). A partir dela são concebidos os projetos institucionais que irão compor o PEI e se converterão nos resultados institucionais das atividades finalísticas, realizados por meio de Planos de Ação e Projetos.

Figura 4 - Cadeia de Valor do Cofen.

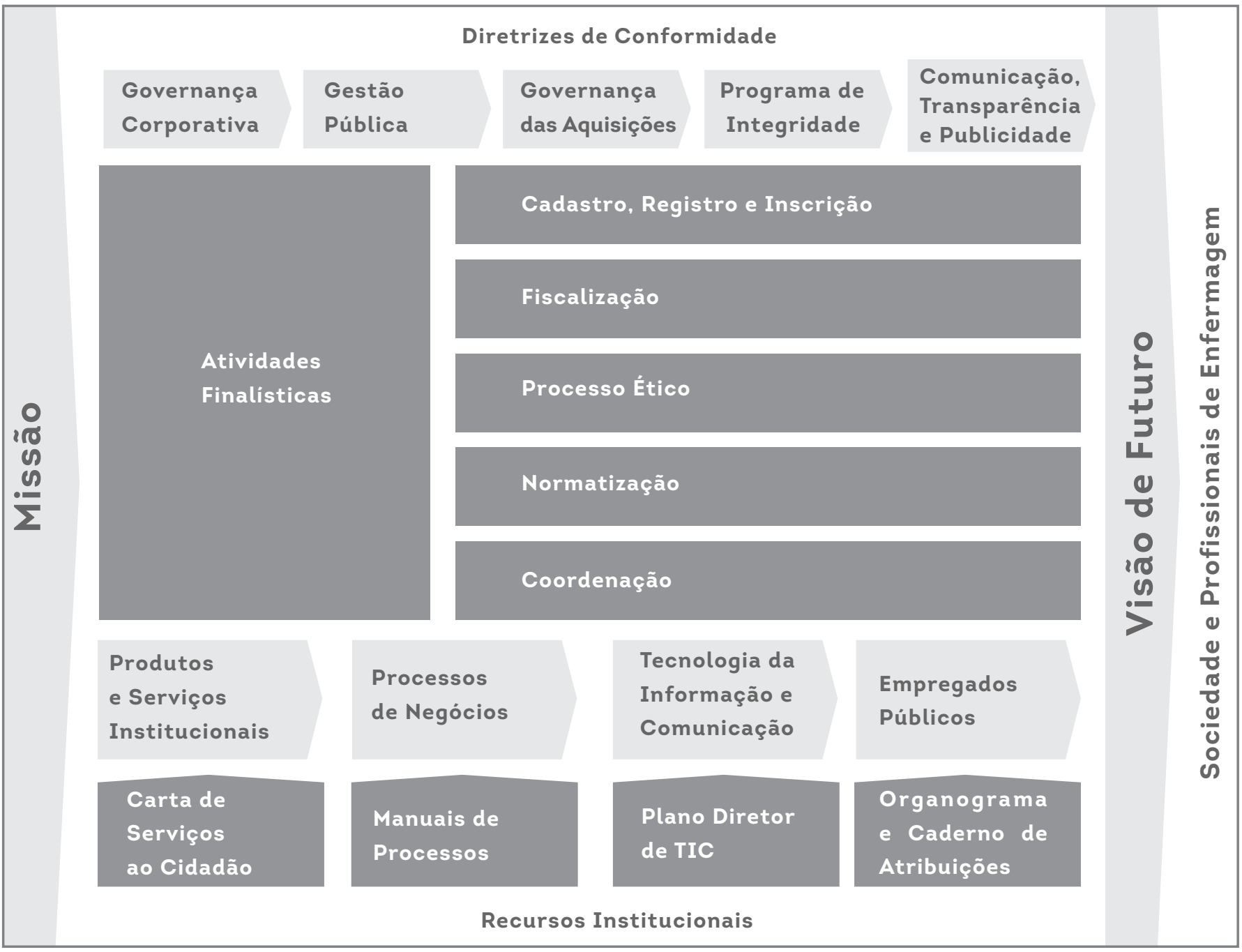

Fonte: Assessoria de Planejamento e Gestão/Cofen. 
O Modelo Negócios do Cofen leva em conta, para a sua concepção, a Cadeia de Valor e é concebido a partir de quatro perguntas fundamentais: O que? Para quem? Como? Quanto? A Figura 5 apresenta esse modelo, o qual está estruturado nas dimensões: Capital, Estratégia, Atividades Finalísticas, Produtos, Impacto e Valor. Onde, entende-se por:

a) Capital: conjunto de recursos que o Cofen possui para realizar as suas Atividades Finalísticas.

b) Estratégia: conjunto de Objetivos Estratégicos organizados nas dimensões da Metodologia do Balanced Scorecard (BSC) adotada pelo Cofen para cumprir a sua Missão Institucional, alcançar a sua Visão de Futuro e realizar as Atividades Finalísticas. c) Atividades Finalísticas: processos que geram e entregam produtos e serviços do Cofen para os Corens, profissionais de enfermagem e sociedade brasileira.

d) Produtos: conjunto de produtos e serviços desenvolvidos pelo Cofen na execução de sua Estratégia, os quais entregam valor percebido aos Corens, à sociedade brasileira e aos profissionais de enfermagem.

e) Impacto: representa a abrangência que as atividades do Cofen desejam alcançar.

f) Valor: representa os resultados precipuos que são entregues ao público-alvo: Corens, profissionais de enfermagem e sociedade brasileira.

Figura 5 - Modelo de Negócio do Cofen.

\section{MODELO DE NEGÓCIO DO COFEN}

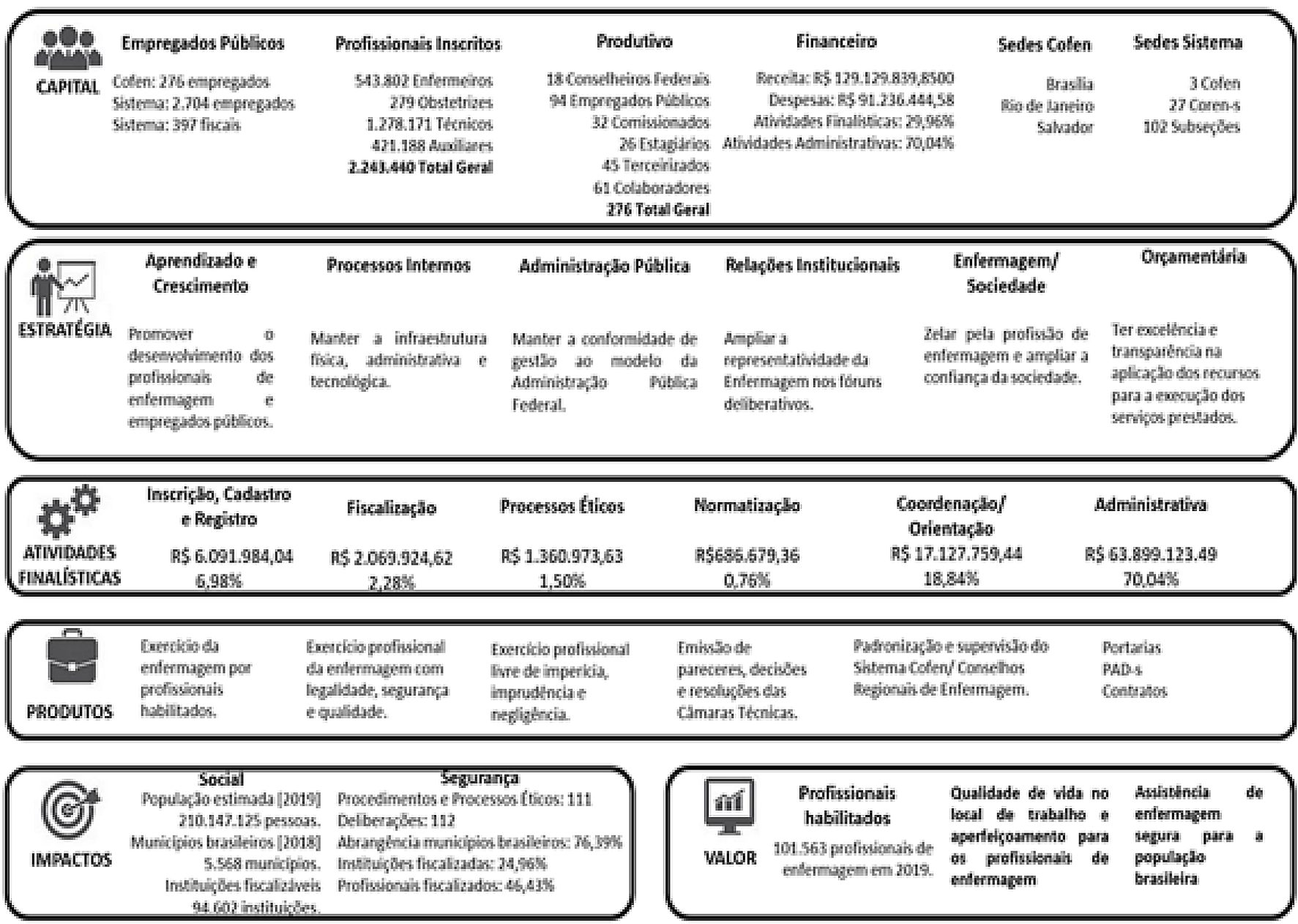

Fonte: Assessoria de Planejamento e Gestão/Cofen. 
O modelo de negócio na esfera pública, também chamados de templates ou canvas, requer pessoal estratégico e qualificado (stakeholders) com capacidade de descrever arranjos de governança para "identificar e modelar indicadores, melhorar o processo decisório, fortalecer o planejamento estratégico, auxiliar o desenho de soluções de [Tecnologia da Informação] TI"7.

\section{Metodologia de Gestão Estratégica Orientada para Resultados (geor)}

O Planejamento Estratégico Institucional (PEI) do Cofen é elaborado utilizando a Metodologia de Gestão Estratégica Orientada para Resultados (GEOR) a qual permite a sociedade e a enfermagem saber dos gestores do Sistema Cofen/Conselhos Regionais de Enfermagem como, onde e com que benefícios os seus recursos estão sendo aplicados. Ela traduz o dever Cofen de explicitar e cristalizar os seus compromissos com a enfermagem por meio do alcance de resultados, transparência e prestação de contas. Resumindo, pode-se dizer que o ponto central da Metodologia GEOR é transformar intenção e ideia em realidade ${ }^{8}$.

Para a aplicação da Metodologia GEOR foi desenvolvido um Método Ágil para concepção, elaboração, execução e acompanhamento de projetos institucionais que utiliza três instrumentos de gestão: SMART, 5W2H e Canvas de Projetos ${ }^{9}$. Cada um dos instrumentos possui um conjunto de perguntas que vão sendo respondidas e contribuem para a elaboração do próximo instrumento (Figura 6).

Figura 6 - Metodologia de Gestão Estratégica Orientada a Resultados.

\section{Iniciativa Estratégica \\ (Oque, Quanto, Quando e Onde) \\ Metodologia SMART \\ Plano de Ação \\ (Quem, Como e Porque) \\ Metodologia 5W2H \\ Projeto \\ (Resultado, Requisitos, Beneficios, Premissa, Restrições, Partes Interessadas) Metodologia $5 \mathrm{~W} 2 \mathrm{H}$}

Fonte: Assessoria de Planejamento e Gestão/Cofen.
Ao final da aplicação da Metodologia GEOR, obtémse Iniciativas Estratégicas que serão utilizadas para a elaboração do Plano Plurianual (PPA), Planejamento Estratégico Institucional, Planejamento Estratégico Setorial e Plano Diretor de Tecnologia da Informação (PDTI), Planos de Ação, Projeto Básicos/Termos de Referência e, finalmente, Contratos de aquisição de bens e serviços.

\section{Atividades Finalísticas e Administrativas}

O Cofen, em 17/01/2018, criou o Departamento de Gestão do Exercício Profissional (DGEP) por meio da Resolução Cofen no 566/2018, para ser o órgão técnico responsável por organizar, planejar, coordenar, executar, supervisionar e avaliar as estratégias necessárias para o alcance das diretrizes de gestão na área das Atividades Finalísticas do Sistema Cofen/Conselhos Regionais de Enfermagem. Para isso, fazem parte de sua estrutura organizacional:

- Câmaras Técnicas são órgãos de natureza consultiva, propositiva e avaliativa sobre assuntos atinentes a enfermagem e assessoram as decisões do Plenário. Assessoria das Câmaras Técnicas é o cargo de assessoramento e suporte à Coordenação das Câmaras Técnicas nas atividades administrativas, assim como também, realizar o atendimento para as Câmaras Técnicas, Comissões, Grupos de Trabalho e colaboradores do Cofen.

- Divisão de Fiscalização do Exercício Profissional (DFEP) é o órgão técnico responsável por executar as estratégias necessárias para a execução das diretrizes e políticas da gestão na área de fiscalização do exercício profissional, objetivando inovar, padronizar, unificar e consolidar as ações que envolvam a fiscalização do exercício profissional.

- Setor de Processos Éticos (SPE) é o órgão operacional responsável por realizar o controle e o cuidado administrativo dos Processos Éticos do Sistema Cofen/Conselhos Regionais de Enfermagem, preparando a documentação necessária, visando o correto andamento e autuação processual.

- Setor de Inscrição, Registro e Cadastro (SIRC) é o órgão técnico responsável por executar 
as estratégias necessárias para o cadastro e inscrição dos profissionais de enfermagem, instituições de saúde, estabelecimentos de ensino e formação profissional de enfermagem.

Atualmente, O DGEP, também, é responsável pela coordenação das atividades das Câmaras Técnicas do Cofen, as quais são de: Atenção à Saúde (CTAS), Educação e Pesquisa (CTEP), Fiscalização (CTFIS), Legislação e Normas (CTLN) e Atenção Básica em Saúde (CTAB).

No exercício de 2019, o Cofen gastou, com as Atividades Finalísticas, $29,96 \%$ do seu orçamento. Estão contemplados nessa porcentagem as Atividades Finalísticas AFOl a AF05, conforme orientações extraídas do Relatório de Fiscalização de Orientação Centralizada (FOC) do Tribunal de Contas da União (TCU), ver tabela 2 e também a figura 4 - Modelo de Negócio do Cofen. A Atividades Finalísticas AFO6 - Administrativa foi criada pelo Cofen para classificar os demais gastos da autarquia que não aqueles classificados pela FOC do TCU (Tabela 1).

Tabela 2 - Gastos por Atividade Finalística.

\begin{tabular}{llll} 
Código & Atividade Finalistica & Valor & Porcentagem \\
AFO1 & $\begin{array}{l}\text { Inscrição, Cadastro e } \\
\text { Registro }\end{array}$ & $6.091 .984,04$ & $6,68 \%$ \\
\hline AF02 & Fiscalização & $2.069 .924,62$ & $2,27 \%$ \\
\hline AF03 & Processo Ético & $1.360 .973,63$ & $1,49 \%$ \\
\hline AF04 & Normatização & $686.679,36$ & $0,75 \%$ \\
\hline AF05 & Coordenação/Orientação & $17.127 .759,44$ & $18,77 \%$ \\
\hline AF06 & Administrativa & $63.899 .123,49$ & $70,04 \%$ \\
\hline
\end{tabular}

Total Geral

$91.236 .444,58 \quad 100,00 \%$

Fonte: Divisão de Orçamento e Empenho/Departamento Financeiro/Cofen.

\section{RESULTADOS DA FISCALIZAÇÃO}

Em busca da uniformidade e fortalecimento do processo de trabalho da fiscalização, a fim de garantir a excelência das ações realizadas pelos Corens, o Cofen tem atuado ativamente realizando visitas técnicas, treinamentos e acompanhamento das condutas adotadas pelos Corens.

No ano de 2019, doze Corens foram contemplados com Visita Técnica da Divisão de Fiscalização do Exercício Profissional/Câmara Técnica de Fiscalização/ Força Nacional de Fiscalização do Cofen nos Departamentos de Fiscalização (DEFIS), objetivando o efetivo acompanhamento e supervisão das atividades de fiscalização realizadas pelos Corens. Um total de cinco Corens foram contemplados com treinamentos e capacitações para enfermeiro fiscais e conselheiros, ainda prestado apoio em apuração de diligências em outros três Corens.

No ano de 2019, foi realizada a Operação de Fiscalização no Coren MT, sendo fiscalizados, pelos membros da Força Nacional de Fiscalização (FNFIS) e fiscais do Coren-MT, 17 estabelecimentos que atendem a maioria absoluta da demanda de saúde do Estado, alcançando cerca de 1.238 leitos e 2.277 profissionais de enfermagem, o que representa, aproximadamente, $10 \%$ dos trabalhadores de enfermagem do Estado do Mato Grosso, sendo detectadas e notificadas 124 não conformidades nos serviços de enfermagem.

Desde 2015, os membros da FNFIS/Cofen já fiscalizaram 150 instituições em onze Estados, sendo identificadas e notificadas cerca de 731 irregularidades/ não conformidades nos serviços de enfermagem. Somente no ano de 2019 foram realizadas, pelos vinte e sete Corens, 24.948 fiscalizações em instituições com serviços de enfermagem em 4.255 municípios do Brasil, alcançando um total de 1.046 .198 profissionais de enfermagem.

Para aprimorar ainda mais a fiscalização, o Cofen estabeleceu, por meio da Resolução Cofen no $598 / 2018$, os Relatórios Trimestrais de Fiscalização e de Processos Éticos, que são preenchidos e enviados ao Cofen, pelos Corens, a cada três meses, em formulário digital para auxiliar no monitoramento, controle e fiscalização do exercício profissional da enfermagem. Esta pesquisa trimestral auxilia a constituição de uma base de informações estratégicas para a construção de programas e projetos de amplitude local e nacional, inclusive para promover, periodicamente, a capacitação continuada dos fiscais dos Corens, com o objetivo de adotar políticas de dinamização dos trabalhos e serviços nessa área, além de atender as demandas de órgãos e entidades de controle externo. O banco de dados resultante do preenchimento dos formulários eletrônicos permite montar tabelas, gráficos e cartogramas de acompanhamento e controle da fiscalização.

\section{RESULTADOS DOS PROCESSOS ÉTICOS}

O Código de Processo Ético, regido pela Resolução Cofen no 370/2010, é o conjunto de instruções que regem a apuração dos indícios de faltas éticas e disciplinares atribuidas à profissionais de enfermagem. 
Ao final dessa apuração ocorre o julgamento ético que é dotado de duplo grau de jurisdição. Na lạ instância está o Plenário dos Corens ou Plenário do Cofen, nos julgamentos de Conselheiros Federais e Regionais ou no impedimento dos Plenários dos Conselhos Regionais. Na 2aㅡ instância, o Plenário do Cofen que atua no julgamento dos recursos das decisões dos Corens, ou a Assembleia de Presidentes, nos recursos em que a primeira instância é o Plenário do Cofen.

O Processo Ético é instaurado mediante: 1) denúncia, que é $o$ ato pelo qual se atribui a alguém a prática de infração ética ou disciplinar, podendo ser realizada por pessoa física ou jurídica; e 2) "De ofício" quando o Presidente do Conselho venha a saber, por qualquer meio, de fato que tenha característica de infração ética ou disciplinar.

Os atos processuais têm caráter reservado, realizando-se, de preferência, na sede dos Conselhos e em dias úteis.

Em 20190 Cofen recebeu 107 recursos de julgamentos de processos éticos realizados pelos Regionais. Além desses, foram instaurados quatro processos administrativos diretamente no Cofen para apurar indícios de infrações ético-disciplinares, sem tramitação prévia em qualquer Coren. Assim, o total de processos que envolvem questões éticas com tramitação no Cofen, foi de 1ll. No cumprimento de suas atividades finalísticas, o Setor de Processos Éticos realizou, no ano de 2019 , nove visitas técnicas a Corens para apoiar e acompanhar as atividades de Processos Éticos.

\section{RESULTADOS DE INSCRIÇÃO, REGISTRO E CADASTRO}

O Setor de Inscrição, Registro e Cadastro (SIRC/ DGEP/Cofen) recebeu 39.901 guias de remessa, as quais geraram 176.383 registros de títulos de qualificação, habilitação e graduação, durante o exercício de 2019.

Além disso, procedeu-se à atualização de 103 cadastros de unidades de ensino e inclusão de 203 novas Instituições de Ensino Superior (IES) no Sistema de Registro. Também foram emitidas, em todo Sistema Cofen/Conselhos Regionais de Enfermagem, 452.346 Carteiras de Identidade Profissional (CIP-s) impressas pelos Corens. Todavia, foram realizadas 29 baixas e seis inclusões no Cadastro Informativo de Créditos Não Quitados do Setor Público Federal (Cadin).

No cumprimento de suas Atividades Finalísticas, o SIRC/ DGEP/Cofen realizou quatro visitas técnicas aos Corens com o objetivo de acompanhar as tarefas desenvolvidas no atendimento, registro dos títulos e inscrição dos profissionais, auxiliando na elaboração de diagnósticos, identificação de falhas nos processos de trabalho dos Corens, medidas de correção e recomendações. Ainda, em 2019, foram passadas, para todos os Corens, orientações referentes aos procedimentos do registro de títulos na modalidade residência, acerca do uso do sistema de geração do número de registro de títulos, procedimentos administrativos de registro e inscrição, registro de título na ausência de diploma e solicitação de urgência nos processos de residência.

\section{RESULTADOS DO PLANEJAMENTO ESTRATÉGICO INSTITUCIONAL}

Os resultados do Planejamento Estratégico Institucional (PEI) são evidenciados por meio do acompanhamento do andamento das Iniciativas Estratégicas e os Processos Administrativos (PADs) em planilhas eletrônicas, nas quais foi aplicada a Metodologia do Balanced Scorecard (BSC) e uma escala de esforço graduada para valorar o progresso das Iniciativas Estratégicas até a sua finalização ${ }^{10-11}$.

O Planejamento Estratégico Institucional (PEI) abrange o periodo de 2018 a 2021 e suas Iniciativas Estratégicas estão classificadas em iniciadas, finalizadas, não iniciadas e canceladas, (Tabela 2).

Tabela 2 - Acompanhamento das Iniciativas Estratégicas.

\begin{tabular}{llllll} 
Descrição & 2018 & 2019 & 2020 & 2021 & Total \\
\hline Iniciativas não iniciadas & 147 & 99 & 99 & 99 & 99 \\
\hline Iniciativas iniciadas & 66 & 19 & 0 & 0 & 85 \\
\hline Iniciativas finalizadas & 26 & 20 & 0 & 0 & 46 \\
Iniciativas canceladas & 3 & 9 & 0 & 0 & 12 \\
Total & & & & & 242
\end{tabular}

Fonte: Assessoria de Planejamento e Gestão/Cofen.

Conforme apresentado pelos instrumentos de controle do Cofen, no ano de 2019, o PEI 2018-2021 avançou para $59 \%$ de execução, conforme pode ser visto na figura 6. Compõe esse resultado: $35 \%$ de Iniciativas Estratégicas iniciadas, $19 \%$ finalizadas, $5 \%$ canceladas e $41 \%$ não iniciadas. A maioria das não iniciadas são para os anos de 2020 e 2021, por essa razão ainda não começaram.

\section{CONCLUSÃO}

Os esforços do Sistema Cofen/Conselhos Regionais 
de Enfermagem para cumprir a sua missão Institucional, principalmente no que diz respeito a manter a conformidade no cumprimento das exigências dos órgãos de controle externos, resulta em uma gestão mais eficiente e profissional do Sistema Cofen/Conselhos Regionais de Enfermagem, dando-lhes a visibilidade como órgãos de referência em Gestão Pública em âmbito nacional, como pode ser comprovado no Levantamento de Governança e Gestão Pública do TCU: Resultados 201712.

OSistema Cofen/Conselhos Regionais de Enfermagem está focado em entregar, cada vez mais, melhores produtos e serviços à sociedade e aos profissionais de enfermagem, realizando, continuamente, a revisão de seus processos de trabalho afim de melhor sua eficiência e eficácia

Todas as ações do Cofen estão canalizadas para a boa prática de governança para o alcance dos objetivos estratégicos relacionados às atividades finalísticas, atendendo normativas legais e assegurando a transparência da gestão quanto a inscrição, cadastro e registro de profissionais; fiscalização do exercício profissional e abertura de processos éticos disciplinares pelo sistema. Conclui-se, que a estrutura organizacional é o principal componente gerencial para importância para execução dos procedimentos metodológicos adotados no planejamento estratégico institucional para o cumprimento das atividades finalísticas.

\section{REFERÊNCIAS}

1. Kissler L, Heidemann FG. Governança pública: novo modelo regulatório para as relações entre Estado, mercado e sociedade? Rev. Adm. Pública, Rio de Janeiro, v. 40, n. 3, p. 479499, June 2006. Available from <http://www.scielo.br/scielo. php?script=sci_arttext\&pid=S0034-76122006000300008\&lng=en\& nrm=iso>. access on 28 Mar. 2020. https://doi.org/10.1590/S003476122006000300008

2. Brasil. Lei no 7.498 , de $25 / 06 / 1986$. Dispõe sobre a regulamentação do exercício da enfermagem, e dá outras providências. Brasilia: 1986. Disponivel em: http://www.planalto.gov.br/ccivil_03/LEIS/L7498.htm. Acesso em: 03/03/2020.

3. Conselho Federal de Enfermagem. Resolução Cofen nํ 421/2012. de 12/02/2012 - Aprova o Regimento Interno do Conselho Federal de Enfermagem e dá outras providências. Brasilia: Cofen, 2012. Disponivel em: <http://www.cofen.gov.br/resoluo-cofen-n-4212012_8670.html>. Acesso em: 03/03/2020.

4. Santos RR, Rover S. Influência da governança pública na eficiência da alocação dos recursos públicos. Rev. Adm. Pública, Rio de Janeiro v. 53, n. 4, p. 732-752, Aug. 2019. Available from <http://www.scielo.br/ scielo. php?script=sci_arttextEpid=\$0034-76122019000400732\&lng= enઈnrm=iso>. access on 28 Mar. 2020. Epub Sep 12, 2019. https://doi. org/10.1590/0034-761220180084

5. Brasil. Lei n 5.905, de 12 de julho de 1973 - Dispõe sobre a criação dos Conselhos Federal e Regionais de Enfermagem e dá outras providências. Brasilia: 1973. Disponivel em: <http://www.planalto.gov. br/ccivil_03/leis/L5905.htm>. Acesso em: 03/03/2020.
6. Conselho Federal de Enfermagem. Enfermagem em números. Disponivel em: http://www.cofen.gov.br/enfermagem-emnumeros. Acesso em: 27/03/2020.

7. Martins HF, Mota JP, Marini C. Modelos de negócio na esfera pública: o modelo canvas de governança pública. Cad. EBAPE. BR, Rio de Janeiro, v. 17, n. 1, p. 49-67, Mar. 2019. Available from <http://www.scielo.br/scielo.php?script=sci_arttext\&pid=S1679$39512019000100006 \varepsilon$ lng=en\&nrm=iso>. access on 28 Mar. 2020. https://doi.org/10.1590/1679-395167893.

8. Persegona MFM, Moura RCD, Freire NP. Heler Junior HV. Metodologia de Gestão Estratégica Orientada para Resultados (GEOR) para o Sistema Cofen-Conselhos Regionais de Enfermagem. Brasilia: Cofen, 2015.

9. Sebrae/NA. Caixa de Ferramentas GEOR. Brasilia: Sebrae Nacional, 2014.

10. Kaplan RS, Norton DP. Organização orientada para Estratégia: como as empresas que adotam o balanced scorecard prosperam no novo ambiente de negócios. Rio de Janeiro: Campus, 2000.

11. Kaplan RS, Norton DP. A Estratégia em Ação: Balanced Scorecard. Rio de Janeiro: Campus, 1997.

12. Brasil. Tribunal de Contas da União. Acórdão no 588/2018 - TCU - Plenário. Relatório de levantamento. Brasilia: Tribunal de Contas da União, 2018. Disponivel em: https://portal.tcu.gov.br/lumis/portal/ file/fileDownload.jsp?fileId=8A81881E6916EE31016917405FFD0DB8.

Recebido: 30/12/2019 - Aceito: 31/03/2020 